\title{
Nanoscale
}

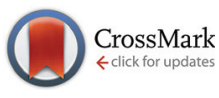

Cite this: Nanoscale, 2015, 7, 14241

Received 23rd February 2015, Accepted 25th July 2015

DOI: $10.1039 / c 5 n r 01239 b$

www.rsc.org/nanoscale

\section{High efficiency air stable organic photovoltaics with an aqueous inorganic contact $\uparrow$}

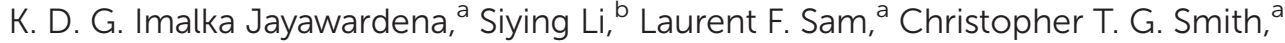 \\ Michail J. Beliatis, ${ }^{a}$ Keyur K. Gandhi, ${ }^{a}$ M. R. Ranga Prabhath, ${ }^{a}$ Thomas R. Pozegic, ${ }^{a}$ \\ Sujie Chen, ${ }^{\mathrm{b}}$ Xiaoli Xu, ${ }^{\mathrm{b}}$ G. Dinesha M. R. Dabera, ${ }^{a}$ Lynn J. Rozanski, ${ }^{a}$ \\ Radu A. Sporea, ${ }^{a}$ Christopher A. Mills, ${ }^{a}$ Xiaojun Guo*b and S. Ravi P. Silva*b
}

\begin{abstract}
We report a $\mathrm{ZnO}$ interfacial layer based on an environmentally friendly aqueous precursor for organic photovoltaics. Inverted PCDTBT devices based on this precursor show power conversion efficiencies of $6.8-7 \%$. Unencapsulated devices stored in air display prolonged lifetimes extending over 200 hours with less than $20 \%$ drop in efficiency compared to devices based on the standard architecture.
\end{abstract}

Solar cells based on blends of organic semiconductors (such as conjugated polymers ${ }^{1,2}$ or small molecules ${ }^{3,4}$ ) and fullerene derivatives are rapidly gaining acceptance as an alternate technology for renewable energy generation. For solution processed organic photovoltaics (OPVs), the bulk heterojunction $(\mathrm{BHJ})$ architecture which consists of an interpenetrating network of the exciton generating organic donor semiconductor and a fullerene based acceptor ${ }^{5}$ is considered to be one of the most effective in terms of device performance. Often, these BHJ films are sandwiched between the ITO anode which has been modified using a poly (3,4-ethylene dioxythiophene): (polystyrene sulfonic acid) (PEDOT:PSS) layer and a reflecting cathode that is modified either with a metal oxide, ${ }^{6}$ metal oxide/graphene ${ }^{7,8}$ or polyelectrolytic interlayer ${ }^{9}$ to fabricate the standard OPV architecture. Whilst this device structure has led to highly efficient devices, it is not favourably looked upon due to the hygroscopic and acidic nature of PEDOT:PSS ${ }^{10,11}$ which degrades the ITO anode resulting in short-lived devices. While the utilisation of carbon nanotubes in place of PEDOT:PSS has been suggested ${ }^{11}$ for standard devices, another route towards

\footnotetext{
${ }^{a}$ Advanced Technology Institute, University of Surrey, Guildford, Surrey, GU2 7XH, UK. E-mail: s.silva@surrey.ac.uk; Fax: +44 (0)1483 68 6081; Tel: +44 (0)1483 689825

${ }^{b}$ National Engineering Lab for TFT-LCD Materials and Technologies, Department of Electronic Engineering, Shanghai Jiao Tong University, Shanghai 200240, People's Republic of China. E-mail: x.guo@sjtu.edu.cn; Fax: +86 02134207734;

Tel: +8602134207734

$\dagger$ Electronic supplementary information (ESI) available: Experimental methods, performance of standard architecture, inverted architecture with $\mathrm{TiO}_{x}$ interlayer, onset of $s$-curves for the standard architecture, photoluminescence of the ZnO film, field effect characteristics of the $\mathrm{ZnO}$ thin films, thermogravimetric analysis of ZnO. See DOI: 10.1039/c5nr01239b
}

alleviating this problem is through the use of the inverted device architecture.

In fabricating inverted devices, the ITO electrode is modified to reduce its work function allowing electron extraction $^{4,12,13}$ as opposed to hole extraction in the standard architecture. ZnO, a II-VI semiconducting material that can be applied using solution based techniques is widely regarded as the "universal material" for modifying the ITO contact. ${ }^{14,15}$ Such ZnO films can be deposited through coating of nanoparticle inks ${ }^{8,12}$ or sol-gel processing. ${ }^{4}$ While the low temperature processable nature of $\mathrm{ZnO}$ is attractive in terms of the requirements for roll-to-roll processing of OPVs, most techniques for deposition of $\mathrm{ZnO}$ such as sol-gel processing present several issues for implementation in roll-to-roll systems. For example, these are often based on hazardous and/ or toxic precursors as well as solvent systems that are unfavorable for roll-to-roll manufacturing. Furthermore, such sol-gel processes are strongly dependent on the ambient humidity levels, ${ }^{16}$ placing and additional control parameter during the deposition of films, and also possess a relatively low shelf life. All of the above factors clearly indicate a strong need for precursors that are moisture insensitive and preferably water based in order to apply to roll-to-roll manufacturing. In addition to the aspects highlighted above, another issue in using such metal oxides in inverted architectures is the occurrence of $S$ shaped electrical curves ${ }^{14}$ due to charge trapping in defect states ${ }^{12}$ on the surface of the metal oxide which necessitates a light soaking treatment for efficient device operation through minimization of charge. In this work, we employ an inorganic ink based on the aqueous ammine-hydroxo complex $\left[\mathrm{Zn}\left(\mathrm{NH}_{x}\right)_{x}\right](\mathrm{OH})_{2}$. This is based on the work reported by Meyers et $a l .{ }^{17}$ where this precursor was used to fabricate $\mathrm{ZnO}$ thin film transistors. Following this work, Bai et al. ${ }^{18}$ reported a modified process of fabricating inverted devices based on blends of poly (3-hexylthiophene) (Р3HT) and [6-6]-phenyl $\mathrm{C}_{61}$ butyric acid methyl ester $\left(\mathrm{PC}_{61} \mathrm{BM}\right)$ using the above ink to form the electron transport layer resulting in devices with power conversion efficiencies (PCEs) in excess of $4 \%$. The notable feature of the work was the excellent performance of the 
inverted device without the requirement for additional UV or ozone treatment ${ }^{12}$ that is often required for inverted OPVs.

Here, we modify the thermal treatment conditions for this aqueous inorganic ink to fabricate highly efficient OPVs based on the polycarbazole semiconducting polymer PCDTBT and $\mathrm{PC}_{71} \mathrm{BM}$ to achieve device processing conditions that are low temperature based and therefore compatible with processing on plastic substrates. PCDTBT, unlike P3HT as well as a majority of polymers used in OPVs, is highly air stable due to its deep highest occupied molecular orbital (HOMO) situated at $\sim 5.6 \mathrm{eV}$ which encourages further development of devices based on this material. Here we show that PCDTBT: $\mathrm{PC}_{71} \mathrm{BM}$ based inverted OPVs which are practically more robust and more compatible with manufacture can achieve a PCE in excess of $7 \%$ which to the best of our knowledge is the highest reported for inverted PCDTBT OPVs. Furthermore, we also investigate the optimal annealing conditions compatible with low cost substrates that lead to improved air stability of these devices, an aspect which has been ignored in previous studies for this system. Based on the optimised annealing conditions, a significantly improved lifetime is achieved resulting in less than a $20 \%$ drop from the initial PCE for un-encapsulated devices over a period approaching 200 hours. While there exists reports of PCDTBT based OPV devices that display longer lifetimes using sol-gel processed $\mathrm{ZnO}$ layers, ${ }^{19}$ these reports indicate lower device efficiencies (compared to the work reported here) achieved at temperatures that are not compatible with low cost, flexible substrates. In comparison, the $\mathrm{ZnO}$ ink used in this work allows higher efficiencies and prolonged lifetimes to be achieved at temperatures compatible with flexible substrates.

The inverted device architecture used in this study: ITO/ZnO/ PCDTBT : $\mathrm{PC}_{71} \mathrm{BM} / \mathrm{MoO}_{x} / \mathrm{Al}$ and the related energy level alignment are shown in Fig. 1(a) and (b) respectively. For all investigations reported here, the active layer ink was prepared using a 1: 4 donor: acceptor ratio and DCB : CB co-solvent system at a $3: 1$ ratio as previously reported by Moon et $a l^{20}$ The formation of the $\mathrm{ZnO}$ thin film as the interfacial layer proceeds according to the reaction scheme as discussed by Meyers et al. ${ }^{17}$

$$
\begin{gathered}
\mathrm{Zn}\left(\mathrm{NO}_{3}\right)_{2(\mathrm{aq})}+2 \mathrm{NaOH}_{(\mathrm{aq})} \rightarrow \mathrm{Zn}(\mathrm{OH})_{2(\mathrm{~s})}+2 \mathrm{NaNO}_{3(\mathrm{aq})} \\
\mathrm{Zn}(\mathrm{OH})_{2(\mathrm{~s})}+\mathrm{xNH}_{3(\mathrm{aq})} \rightarrow \mathrm{ZnO}_{(\mathrm{s})}+\mathrm{xNH}_{3(\mathrm{~g})}+\mathrm{H}_{2} \mathrm{O}_{(\mathrm{aq})}
\end{gathered}
$$

Optical transmission spectroscopic investigations carried out on ZnO coated ITO substrates (Fig. 1(c)) indicates that, within the wavelength region in which light absorption by PCDTBT occurs, more than $80 \%$ of the light is transmitted onto the active layer through the $\mathrm{ZnO} / \mathrm{ITO}$ with a maximum transmission approaching 90\%. Furthermore, there appears to be more than a $20 \%$ loss in light transmission below $475 \mathrm{~nm}$. However, this is not considered to be significantly detrimental to the device performance as there is no significant absorption by the polymer in this region. The significant light transmission observed in the wavelength region of $500 \mathrm{~nm}$ and above is considered to be ideal for maximizing the photon harvesting by the active layer in order to obtain high incident photon to current conversion efficiencies (IPCE).

Previously, we have shown that although interfacial layers for different active layer systems can yield high performing devices, appropriate material selection is required in order to yield the best performance. While inorganic $\mathrm{ZnO}$ ink has been shown to perform satisfactorily with P3HT, there is no work available in the literature on its usage or suitability for PCDTBT. Such a study is especially important as PCDTBT is now widely seen as a suitable successor to P3HT not only due to its higher efficiency, but also its better stability and longer lifetime. In order to assess the suitability of $\mathrm{ZnO}$ the precursor solution based on the ammine ligand-hydroxo complex studied here, the performance of OPV devices with and without the $\mathrm{ZnO}$ interfacial layers were studied (Fig. 2(a)) and the resulting device performance parameters given in Table 1.

For the device performance parameters obtained, it is evident that in the absence of $\mathrm{ZnO}$, the devices suffer from low (a)

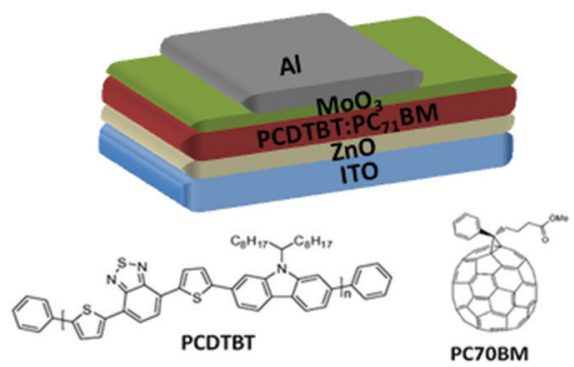

(b)

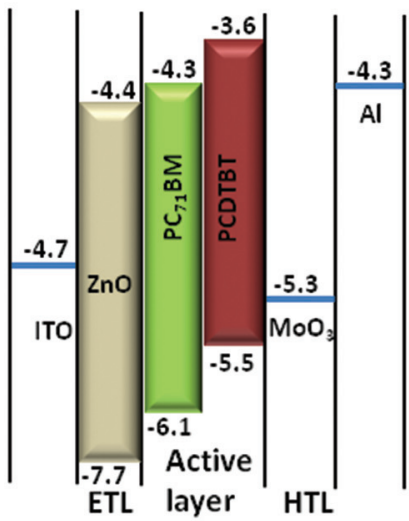

(c)

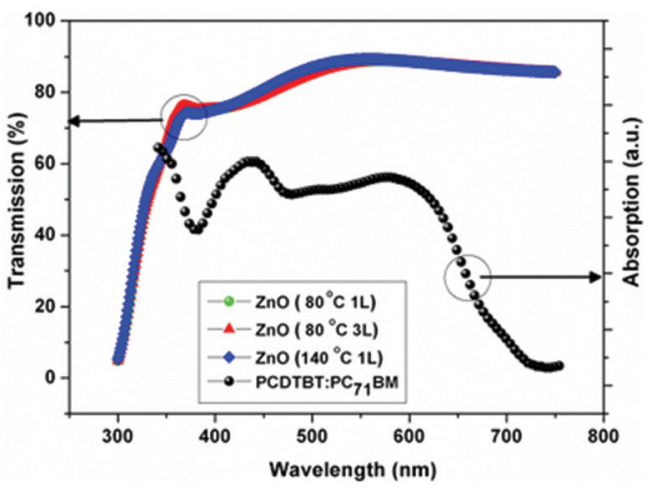

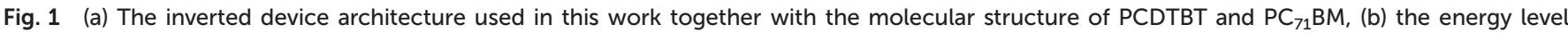

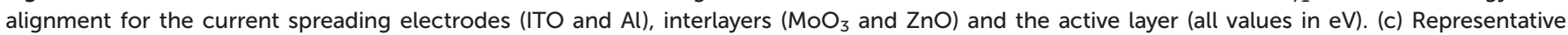

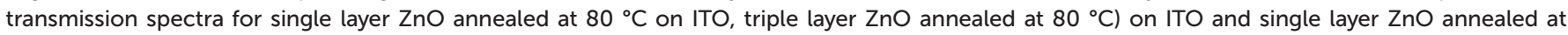
$140{ }^{\circ} \mathrm{C}$ on ITO. The absorption spectrum of PCDTBT : $\mathrm{PC}_{71} \mathrm{BM}$ is also given. 

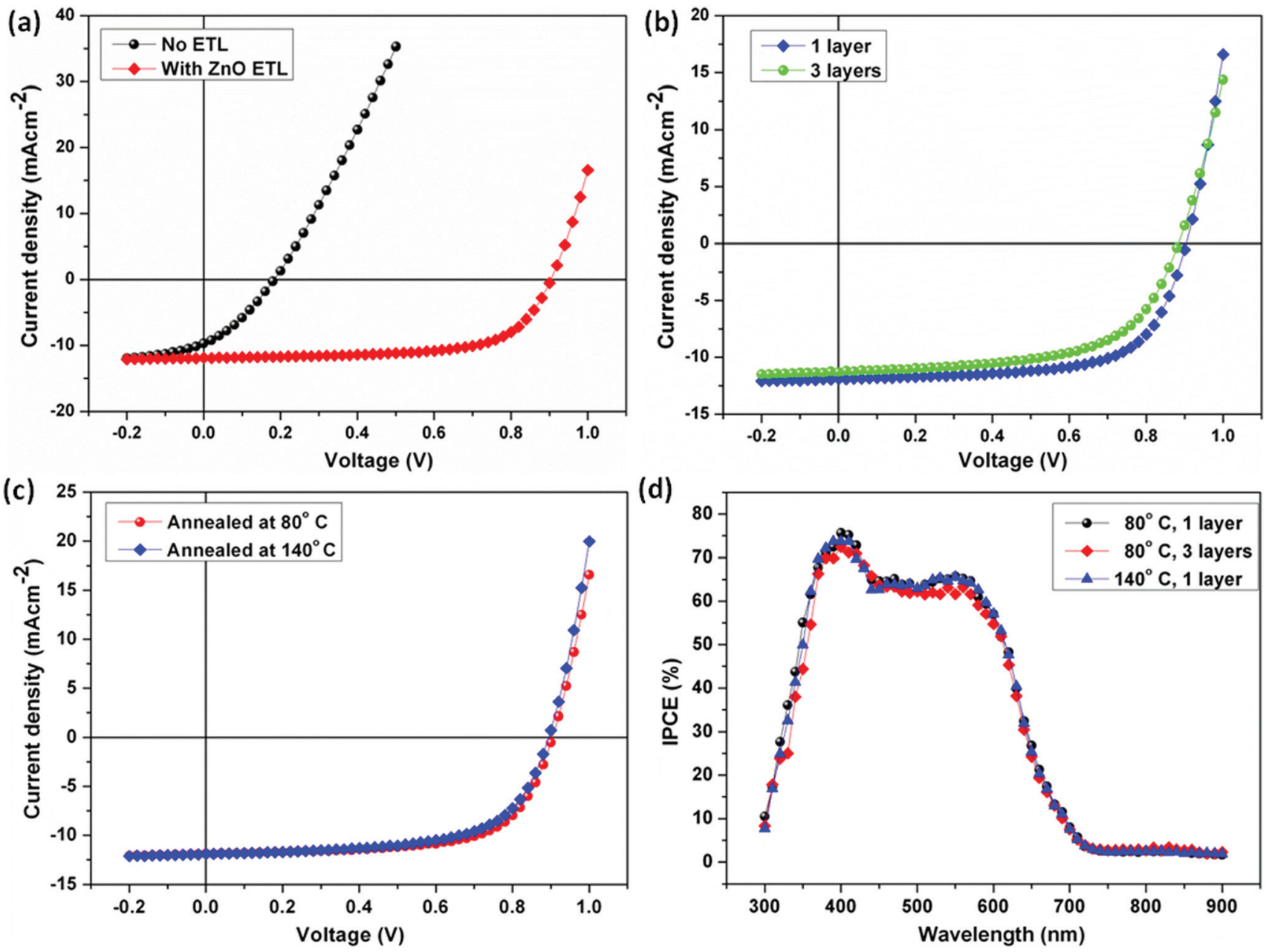

Fig. 2 Comparison of device performance for (a) devices with and without $\mathrm{ZnO}$ interlayer (spin coated once and annealed at $80{ }^{\circ} \mathrm{C}$ ) and (b) devices with $\mathrm{ZnO}$ interlayer spin coated once and thrice (both annealed at $80^{\circ} \mathrm{C}$ ). (c) Characteristics for devices with $\mathrm{ZnO}$ interlayer annealed at $80{ }^{\circ} \mathrm{C}$ and $140^{\circ} \mathrm{C}$ and (d) the IPCE spectra of devices with $\mathrm{ZnO}$ interlayers prepared under different conditions.

Table 1 Comparison of device performance characteristics for reference devices (without the $\mathrm{ZnO}$ layer) and for devices with one and three coatings of $\mathrm{ZnO}$ interlayers

\begin{tabular}{lccllll}
\hline Device & $\begin{array}{l}V_{\mathrm{oc}} \\
(\mathrm{V})\end{array}$ & $\begin{array}{l}J_{\mathrm{sc}} \\
\left.(\mathrm{mA} \mathrm{cm})^{-2}\right)\end{array}$ & $\mathrm{FF}$ & $\operatorname{PCE}(\%)$ & $\begin{array}{l}R_{\mathrm{s}} \\
\left(\Omega \mathrm{cm}^{2}\right)\end{array}$ & $\begin{array}{l}R_{\mathrm{sh}} \\
\left(\Omega \mathrm{cm}^{2}\right)\end{array}$ \\
\hline Reference & 0.18 & 9.72 & 33.31 & 0.58 & 12.8 & 30.4 \\
ZnO (1L) & 0.90 & 11.84 & 63.86 & $6.81(7.09)$ & 8.1 & 943.3 \\
ZnO (3L) & 0.88 & 11.90 & 60.04 & 5.98 & 10.8 & 1415
\end{tabular}

open circuit voltage $\left(V_{\mathrm{oc}}\right)$ and low fill factors, the latter driven by low shunt resistances. Low shunt resistances are typically considered to be an indication of leakage currents that arise from recombination of generated charge carriers thereby minimising the quantity of charges extracted as is evident from the drop in the short circuit current density $\left(J_{\mathrm{sc}}\right)$. The low $V_{\text {oc }}$ observed in the absence of the $\mathrm{ZnO}$ layer is less than the work function difference between ITO $(4.7 \mathrm{eV})$ and $\mathrm{MoO}_{x}$
$(5.3 \mathrm{eV})$ by $\sim 0.4 \mathrm{eV}$. The $V_{\mathrm{oc}}$ for the devices with $\mathrm{ZnO}$ interlayers are observed to be at $0.9 \mathrm{eV}$, similar to the values observed in standard PCDTBT: $\mathrm{PC}_{71} \mathrm{BM}$, the loss of $\sim 0.4 \mathrm{eV}$ indicates the formation of a barrier at the ITO contact. While the average PCE of $6.8 \%$ with a highest recorded value of $\sim 7.1 \%$ is slightly below the best observed with the $\mathrm{TiO}_{x}$ interlayer (Fig. S1 and Table S1 $\dagger$ ), the performances reported here are noted to be better than those reported using either sol-gel processed $\mathrm{ZnO}$ interfacial layers, ${ }^{19} \mathrm{ZnO}$ nanoparticles ${ }^{21}$ or polyelectrolytic interlayers $^{22}$ (we also tested inverted devices replacing the $\mathrm{ZnO}$ interlayer with the $\mathrm{TiO}_{x}$ interlayer. However, the devices failed to show diode characteristics indicating that the $\mathrm{TiO}_{x}$ interlayer is unsuitable for this configuration (Fig. S2 $\dagger$ )). The $J_{\mathrm{sc}}$ as well as the fill factors (FFs) for the inverted devices are slightly lower than of that observed for devices fabricated using the standard architecture with PEDOT:PSS and $\mathrm{TiO}_{x}$ as the interfacial layers (Fig. S1 and Table $\mathrm{S} 1 \dagger)$. The slight drop in $J_{\mathrm{sc}}$ is attributed to the decrease in the light transmission through ITO/ZnO at wavelengths below $475 \mathrm{~nm}$. 

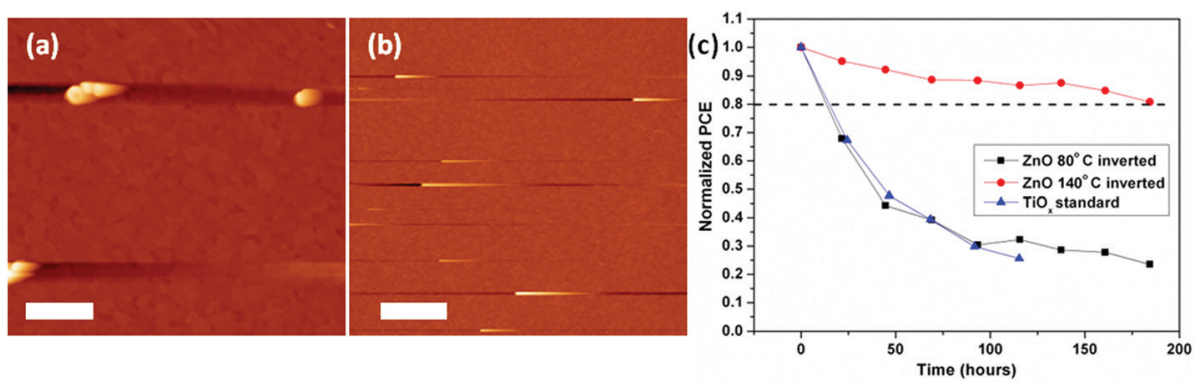

Fig. 3 Atomic force micrographs of $\mathrm{ZnO}$ thin films spin coated and annealed at (a) $80^{\circ}$ and (b) at $140{ }^{\circ} \mathrm{C}$. While particulates can be observed in both films, they are noted to be larger for the former. The scale bars indicate $1 \mu \mathrm{m}$. Figure (c) indicates the variation in the power conversion efficiency for inverted solar cells incorporating $\mathrm{ZnO}$ interfacial layers prepared at $\sim 80^{\circ} \mathrm{C}$ and $\sim 140^{\circ} \mathrm{C}$ compared to the variation in performance for standard solar cells incorporating a $\mathrm{TiO}_{x}$ interfacial layer normalized to their initial values. All devices measured and stored in air and are not encapsulated. Inverted devices that utilize $\mathrm{ZnO}$ thin films prepared at $140^{\circ} \mathrm{C}$ show high stability compared to the other devices studied here.

In order to understand the reduction in $\mathrm{FF}$, atomic force micrographs were obtained for $\mathrm{ZnO}$ thin films coated on ITO substrates (Fig. 3). From the AFM scans, it is noted that the $\mathrm{ZnO}$ thin films, irrespective of the annealing temperature used, display particulates on the surface. However, the particulates are observed to be larger for the films that are prepared at the lower annealing temperature $\left(\sim 80^{\circ} \mathrm{C}\right)$ while smaller particulates are observed for the films prepared at $\sim 140{ }^{\circ} \mathrm{C}$. The lower annealing temperatures lead to a higher root mean square $\left(r_{\mathrm{q}}\right)$ and mean $\left(r_{\mathrm{a}}\right)$ surface roughness of $\sim 9.6 \mathrm{~nm}$ and $3.46 \mathrm{~nm}$ (respectively) while the higher annealing temperature results in a lower $r_{\mathrm{q}}$ and $r_{\mathrm{a}}$ values of $\sim 3 \mathrm{~nm}$ and $\sim 1.7 \mathrm{~nm}$ (respectively). As will be discussed later, the presence of these particulates is likely to be due to the incomplete reaction of the precursor which is more effective at temperatures above $100{ }^{\circ} \mathrm{C}$. The resulting particulates can also add to an increase in the series resistance leading to the slightly lower fill factor observed for the inverted devices in this work compared to devices based on the standard architecture.

Following the above observation, devices were fabricated by spin coating multiple layers of $\mathrm{ZnO}$ sequentially with a thermal treatment carried out after each spin coating step in order to minimize the dissolution of the formed layer by the subsequent spin coating process. Optical transmission spectra of $\mathrm{ZnO} / \mathrm{ITO}$ samples formed by spin coating the precursor to form one layer (1L) and three times, to form a thicker layer (3L) (Fig. 1(c)) does not indicate a significant decrease in the optical transmission to a level that is detrimental to the photon harvesting capability of the active layer. This may be partly due to the slight dissolution of the underlying $\mathrm{ZnO}$ layer as a result of the $\mathrm{NH}_{4} \mathrm{OH}$ in the inorganic ink. A comparison of the performance characteristics for devices prepared with $1 \mathrm{~L}$ and $3 \mathrm{~L}$ are given in Fig. 2 (b) with the performance parameters for the latter shown in Table 1. Analysis of the characteristics indicates that the devices prepared using $3 \mathrm{~L}$ of $\mathrm{ZnO}$ show a slight drop in $V_{\mathrm{oc}}$ combined with a noticeable drop in the FF driven by an increased $R_{\mathrm{S}}$ and $R_{\mathrm{sh}}$. This indicates that despite its semiconducting nature, a thin layer of $\mathrm{ZnO}$ is preferable over a thicker layer that planarizes the underlying ITO
Table 2 Comparison of device performance characteristics for devices with the $\mathrm{ZnO}$ layer prepared under different annealing conditions

\begin{tabular}{lllllll}
\hline Temperature & $\begin{array}{l}V_{\mathrm{oc}} \\
(\mathrm{V})\end{array}$ & $\begin{array}{l}J_{\mathrm{sc}} \\
\left.(\mathrm{mA} \mathrm{cm})^{-2}\right)\end{array}$ & FF & $\begin{array}{l}\mathrm{PCE} \\
(\%)\end{array}$ & $\begin{array}{l}R_{\mathrm{s}} \\
\left(\Omega \mathrm{cm}^{2}\right)\end{array}$ & $\begin{array}{l}R_{\mathrm{sh}} \\
\left(\Omega \mathrm{cm}^{2}\right)\end{array}$ \\
\hline $80^{\circ} \mathrm{C}$ & 0.90 & 11.84 & 63.86 & 6.81 & 8.1 & 943.3 \\
$140^{\circ} \mathrm{C}$ & 0.90 & 11.92 & 62.73 & 6.73 & 7.5 & 943.3
\end{tabular}

contact and that in this case, helps optimize the lateral conduction properties to improve $V_{\text {oc }}$ and $\mathrm{FF}$ rather than only acting to planarize ITO for reduction of leakage currents.

In all of the investigations discussed above, the thermal treatment for the formation of the $\mathrm{ZnO}$ interlayer was carried out at a low temperature of $80{ }^{\circ} \mathrm{C}$ which is often deemed as being the temperature around which the reactions involving zinc precursors such as those presented in eqn (1) and (2) are observed to proceed. ${ }^{23,24}$ However, it is interesting to note how altering the annealing temperature for formation of the $\mathrm{ZnO}$ interlayer would affect the device performance. For this purpose, the performance of devices with $\mathrm{ZnO}$ formed by annealing at $\sim 80^{\circ} \mathrm{C}$ and $\sim 140{ }^{\circ} \mathrm{C}$ were compared. Representative device performance characteristics, IPCE spectra and the device performance parameters are shown in Fig. 2(c) and (d) and Table 2 respectively. From the results obtained it is evident that irrespective of the annealing temperature used for preparation of $\mathrm{ZnO}$, the performance characteristics remain similar during the initial measurements.

One principle motivation behind the development of inverted OPVs is the capability to process more air stable device architectures through the use of oxygen and moisture scavenging interfacial layers combined with the more air stable $\mathrm{Ag}$ as the back reflecting electrode. ${ }^{14,25}$ Furthermore, PCDTBT is expected to be a more air stable polymer with a possible estimated lifetime of 7 years, which is a direct outcome of its deeper HOMO level. ${ }^{26,27}$ Therefore, it is considered to be of interest and importance to study the stability of such systems with cheaper back reflecting electrodes such as Al. Furthermore, in relation to the work discussed pre- 
viously, it would be interesting to see if the performance of the devices display similar levels of stability irrespective of the $\mathrm{ZnO}$ annealing temperature.

For this purpose, the performance of three device architectures; i.e.,

(i) $\mathrm{ITO} / \mathrm{ZnO}\left(80^{\circ} \mathrm{C}\right) / \mathrm{PCDTBT} / \mathrm{MoO}_{x} / \mathrm{Al}$,

(ii) $\mathrm{ITO} / \mathrm{ZnO}\left(140^{\circ} \mathrm{C}\right) / \mathrm{PCDTBT} / \mathrm{MoO}_{x} / \mathrm{Al}$ and

(iii) ITO/PEDOT:PSS/PCDTBT/TiO ${ }_{x} / \mathrm{Al}$ (standard non-inverted architecture),

were studied for a period of several days in the absence of encapsulation. All measurements were conducted in air and the devices stored in ambient under fluroscent light between each measurement to obtain a more realistic evaluation of the device stability under standard air exposure. The variation in PCE (normalized to the initial value of each type) are shown in Fig. 3(c).

Based on the normalized PCE values for the three architectures studied, it is evident that despite using the same material as the interfacial layer, the stability of the devices are significantly affected by the treatment temperatures for ZnO. The higher $\mathrm{ZnO}$ temperature leads to a more stable device architecture whose PCE is retained within $80 \%$ of the initial value over a period of $\sim 180$ hours. The PCE of devices with ZnO prepared at lower temperature drops to below $80 \%$ within a very short duration of 15 hours. The stability of the devices observed for the former conditions is considered to be exceptional, especially as the measurements have been conducted by storing the device in air in the absence of device encapsulation making the inorganic ink used here one of the few unique systems that improves the longevity of the device whilst also negating the need for light soaking for realistic device operation. In terms of stability comparison between the inverted and standard architectures, the stability of the inverted devices with the low temperature processed $\mathrm{ZnO}$ layer is observed to be comparable in terms of the PCE observed in the standard architecture with the $\mathrm{TiO}_{x}$ layer. However, we note that unlike in the case of the inverted devices, the standard device begins to show an S shaped characteristics (Fig. S3 $\dagger$ ) which is usually attributed to unbalanced charge extraction as a result of charge trapping. As $\mathrm{TiO}_{x}$ is generally known to scavenge moisture and oxygen, ${ }^{28}$ it is unlikely that degradation at a level significant to affect the device performance occurs at the $\mathrm{TiO}_{x} / \mathrm{Al}$ contact. Therefore, the poor device performance and the $\mathrm{S}$ shaped characteristics is attributed to the degradation of ITO as a result of the acidic nature of PEDOT:PSS which results in unbalanced charge extraction leading to the observed characteristics, a result which can be alleviated with the use of the inverted structure and the $\mathrm{ZnO}$ ink used herein.

Having understood the implication of different treatment temperatures on the $\mathrm{ZnO}$ precursor on device stability, it is important to understand the causes behind the better performance for the inverted devices that utilize the $\mathrm{ZnO}$ interlayer prepared under the higher annealing temperature. Due to the lack of encapsulation on the devices studied herein, degradation could proceed both at the $\mathrm{ZnO}$ interlayer as well as within the active layer. One potential route towards evaluation of whether the $\mathrm{ZnO}$ interlayer degrades is through evaluation of its photoluminescence (PL) spectrum over time. For this purpose, the PL spectra of ZnO films deposited $80^{\circ} \mathrm{C}, 100{ }^{\circ} \mathrm{C}, 120{ }^{\circ} \mathrm{C}$ and $140{ }^{\circ} \mathrm{C}$ were measured within $2-3$ hours after deposition as well as 4 days after deposition (Fig. S4†). The annealing temperatures were limited to the above temperatures as our purpose was to evaluate the suitability of this precursor for roll-to-roll systems where the flexible substrates used cannot exceed $140{ }^{\circ} \mathrm{C}$. While there was a clearly observable green emission for the $\mathrm{ZnO}$ films annealed at $80^{\circ} \mathrm{C}$ both in as-deposited state as well as when measured after a few days, a similar green emission was not observed for the remaining films indicating their stability as well as lower defect content. As the green emission of $\mathrm{ZnO}$ is correlated to radiative defect states in the film, ${ }^{16,29}$ this is indicative that at higher annealing temperatures, less defective $\mathrm{ZnO}$ thin films are produced, presumably due to a better conversion of the precursor which is supported by the discussion on thermogravimetric analysis to follow.

An indirect route towards supporting the above conclusion from the photoluminescence spectra (i.e. the more defective nature of $\mathrm{ZnO}$ films prepared at sub $100{ }^{\circ} \mathrm{C}$ ) is through analysis of charge mobility in the $\mathrm{ZnO}$ film. Therefore, to evaluate the electron mobility in these films, field effect measurements were carried out using a bottom gate top contact architecture, with $\mathrm{Al}$ source and drain contacts. The performance characteristics of these thin film transistors are given in Fig. S5† together with the relevant parameters in Table S1. $\dagger$ Analysis of the characteristics indicates that both devices prepared using a single layer of $\mathrm{ZnO}$ show standard transistor performance and operate as an n-channel enhancement mode device. Furthermore, the average field-effect mobility of the ZnO TFT prepared at $140{ }^{\circ} \mathrm{C}$ display a higher carrier mobility of $\sim 0.55 \mathrm{~cm}^{2} \mathrm{~V}^{-1} \mathrm{~s}^{-1}$ compared to the lower value of $0.02 \mathrm{~cm}^{2} \mathrm{~V}^{-1} \mathrm{~s}^{-1}$ for the films prepared at $80^{\circ} \mathrm{C}$. This indicates that the annealing temperature plays an important role in the electronic properties of these $\mathrm{ZnO}$ thin films.

As there is no apparent degradation in the $\mathrm{ZnO}$ interlayer, it is more than likely that the degradation of the device proceeds through the active layer itself. This becomes evident as the device parameters are evaluated over time for the devices consisting of the $\mathrm{ZnO}$ interlayers annealed at $80{ }^{\circ} \mathrm{C}$ and $140{ }^{\circ} \mathrm{C}$. The rapid degradation in PCE in the former devices as observed in Fig. 3(c) however does not appear to lead to the formation of " $S$ " shaped curves as was the case for the standard devices (Fig. S3 $\dagger$ ) and the analysis of the $J-V$ curves for inverted devices with $\mathrm{ZnO}$ inverted layers prepared at $80{ }^{\circ} \mathrm{C}$ and $140{ }^{\circ} \mathrm{C}$ indicates diode-like curves (Fig. S6 $\dagger$ ). This in fact indicates that the major degradation pathway is through the active layer, especially for the former device. This view is further supported by the concomitant decrease in all device parameters (Fig. S7 $\dagger$ ) over time for both devices, but more so for the devices with the $\mathrm{ZnO}$ interlayer annealed at $80^{\circ} \mathrm{C}$.

From the above, it is evident that despite similar high performance at an initial stage, devices with ZnO thin films 
prepared at lower annealing temperatures (such as $80{ }^{\circ} \mathrm{C}$ ) are susceptible to rapid degradation compared to devices with the $\mathrm{ZnO}$ thin films prepared with higher annealing temperatures. Therefore, to better understand the nature of reactions that may proceed with changing (of annealing) temperature, thermogravimetric analysis (TGA) on traces of the $\mathrm{ZnO}$ precursor solutions were also conducted (Fig. S8 $\dagger$ ). From the TGA curve, it is evident that there is a significant weight loss of $\sim 18 \%$ for temperatures in the range of $50-100{ }^{\circ} \mathrm{C}$ which is below that of the boiling point of water. The variation in weight in this temperature region is in agreement with the hydroxide formation, oxidation and crystallization that happen for this precursor system below $100{ }^{\circ} \mathrm{C} .{ }^{17,23}$ Furthermore, when the temperature is increased beyond $100{ }^{\circ} \mathrm{C}$, there is a further weight loss which is attributed to the loss of a number of species, especially chemisorbed water. This suggests that under the lower annealing temperatures (such as $80^{\circ} \mathrm{C}$ ), there is likelihood that both the unreacted species as well as moisture will be present within the device compared to films annealed at higher temperatures (such as $140{ }^{\circ} \mathrm{C}$ ). It is also noted here that the possible presence of a higher moisture content in the $\mathrm{ZnO}$ films is in agreement with the relatively quicker degradation of devices with $\mathrm{ZnO}$ films prepared at $80{ }^{\circ} \mathrm{C}$ as opposed to $140{ }^{\circ} \mathrm{C}$ as is often expected for organic semiconductors. Therefore, further investigations are required to ascertain effects of higher annealing temperatures that are compatible with low cost plastic substrates to mitigate such detrimental properties of the precursor. However, it should be noted that under the conditions studied here, the $\mathrm{ZnO}$ ink used in this work shows significant promise for use in roll-toroll processed organic photovoltaic modules, particularly with the annealing step involved post-deposition of the ink.

\section{Conclusions}

In conclusion, a "green" ZnO precursor solution ink has been utilized to fabricate $\mathrm{ZnO}$ thin films as an interlayer for inverted organic solar cells. While the annealing temperatures of $80^{\circ} \mathrm{C}$ and $140{ }^{\circ} \mathrm{C}$ both lead to comparable performance at the outset, measurements carried out over longer durations reveal a significantly improved lifetime for devices that utilize the $\mathrm{ZnO}$ thin films prepared at $140{ }^{\circ} \mathrm{C}$ with only $20 \%$ loss in the initial power conversion efficiency over 200 hours. This is observed in the absence of device encapsulation and storage of devices in air. The principle degradation in the devices with $\mathrm{ZnO}$ annealed at $80{ }^{\circ} \mathrm{C}$ is due to the residual moisture within the $\mathrm{ZnO}$ layer which over time degrades the active layers resulting in a reduction of all device performance parameters leading to a power conversion efficiency loss. On the other hand, this situation is mitigated under higher annealing conditions where a majority of the residual moisture and unreacted precursor species are removed resulting in a longer lifetime. The excellent device performance combined with the good device stability under non-ideal device encapsulation conditions using the green $\mathrm{ZnO}$ precursor in this work is expected to catalyse the development of long lifetime roll-toroll processed organic photovoltaic modules.

\section{Acknowledgements}

The authors would like to thank E.ON International Research Initiative and the Surrey Knowledge Transfer Account for funding the work described here. The authors are also grateful to EPSRC for the Postdoctoral Fellowships awarded (K. D. G. I. J. (EP/K503186) and M. J. B. (EP/P503752)), the Royal academy of Engineering for the fellowship (R. A. S.), the Santander Bank for the visiting studentships (S. L. and S. C.) the University of Surrey for the Overseas Research Student Scholarship and the University Research Student Scholarships (ORS/URS) (G. D. M. R. D.) and the South East Physics Network for the Scholarship awarded (M. R. R. P.). This work is also supported by the Ph.D. Programs Foundation of Ministry of Education of China (20120073110093) and National Natural Science Foundation of China (Grant No. 61274083, 61334008). The authors would also like to thank the reviewers for the helpful comments. The authors acknowledge funding from EPSRC (UK). The authors confirm that data underlying the findings are available without restriction. Details of the data and how to request access are available from the University of Surrey publications repository, http://dx.doi.org/10.15126/ surreydata.00808257.

\section{Notes and references}

1 Y. Y. Liang, Z. Xu, J. B. Xia, S. T. Tsai, Y. Wu, G. Li, C. Ray and L. P. Yu, Adv. Mater., 2010, 22, E135-E138.

2 X. Guo, N. Zhou, S. J. Lou, J. Smith, D. B. Tice, J. W. Hennek, R. P. Ortiz, J. T. L. Navarrete, S. Li, J. Strzalka, L. X. Chen, R. P. H. Chang, A. Facchetti and T. J. Marks, Nat. Photonics, 2013, 7, 825-833.

3 Y. M. Sun, G. C. Welch, W. L. Leong, C. J. Takacs, G. C. Bazan and A. J. Heeger, Nat. Mater., 2012, 11, 44-48.

4 A. K. K. Kyaw, D. H. Wang, V. Gupta, J. Zhang, S. Chand, G. C. Bazan and A. J. Heeger, Adv. Mater., 2013, 25, 23972402.

5 G. Yu, J. Gao, J. C. Hummelen, F. Wudl and A. J. Heeger, Science, 1995, 270, 1789-1791.

6 S. H. Park, A. Roy, S. Beaupre, S. Cho, N. Coates, J. S. Moon, D. Moses, M. Leclerc, K. Lee and A. J. Heeger, Nat. Photonics, 2009, 3, 297-U295.

7 M. J. Beliatis, K. K. Gandhi, L. J. Rozanski, R. Rhodes, K. D. G. I. Jayawardena, S. J. Henley and S. R. P. Silva, Adv. Mater., 2014, 26, 2078-2083.

8 K. D. G. I. Jayawardena, R. Rhodes, K. K. Gandhi, M. R. R. Prabhath, G. D. M. R. Dabera, M. J. Beliatis, L. J. Rozanski, S. J. Henley and S. R. P. Silva, J. Mater. Chem. A, 2013, 1, 9922-9927.

9 Z. He, C. Zhong, X. Huang, W.-Y. Wong, H. Wu, L. Chen, S. Su and Y. Cao, Adv. Mater., 2011, 23, 4636-4643. 
10 R. A. Hatton, N. P. Blanchard, V. Stolojan, A. J. Miller and S. R. P. Silva, Langmuir, 2007, 23, 6424-6430.

11 G. D. M. R. Dabera, K. D. G. I. Jayawardena, M. R. R. Prabhath, I. Yahya, Y. Y. Tan, N. A. Nismy, H. Shiozawa, M. Sauer, G. Ruiz-Soria, P. Ayala, V. Stolojan, A. A. D. T. Adikaari, P. D. Jarowski, T. Pichler and S. R. P. Silva, ACS Nano, 2013, 7, 556-565.

12 S. Chen, C. E. Small, C. M. Amb, J. Subbiah, T. H. Lai, S. W. Tsang, J. R. Manders, J. R. Reynolds and F. So, Adv. Energy Mater., 2012, 2, 1333-1337.

13 Z. He, C. Zhong, S. Su, M. Xu, H. Wu and Y. Cao, Nat. Photonics, 2012, 6, 593-597.

14 J. You, C.-C. Chen, L. Dou, S. Murase, H.-S. Duan, S. Hawks, T. Xu, H. J. Son, L. Yu, G. Li and Y. Yang, Adv. Mater., 2012, 24, 5267-5272.

15 J. B. You, L. T. Dou, K. Yoshimura, T. Kato, K. Ohya, T. Moriarty, K. Emery, C. C. Chen, J. Gao, G. Li and Y. Yang, Nat. Commun., 2013, 4, 1446.

16 S. J. Han, A. A. D. T. Adikaari, K. D. G. I. Jayawardena, N. A. Nismy and S. R. P. Silva, J. Appl. Phys., 2012, 112.

17 S. T. Meyers, J. T. Anderson, C. M. Hung, J. Thompson, J. F. Wager and D. A. Keszler, J. Am. Chem. Soc., 2008, 130, 17603-17609.

18 S. Bai, Z. W. Wu, X. L. Xu, Y. Z. Jin, B. Q. Sun, X. J. Guo, S. S. He, X. Wang, Z. Z. Ye, H. X. Wei, X. Y. Han and W. L. Ma, Appl. Phys. Lett., 2012, 100.
19 Y. Sun, J. H. Seo, C. J. Takacs, J. Seifter and A. J. Heeger, Adv. Mater., 2011, 23, 1679-1683.

20 J. S. Moon, J. Jo and A. J. Heeger, Adv. Energy Mater., 2012, 2, 304-308.

21 V. S. Gevaerts, A. Furlan, M. M. Wienk, M. Turbiez and R. A. J. Janssen, Adv. Mater., 2012, 24, 2130-2134.

22 R. D. Xia, D. S. Leem, T. Kirchartz, S. Spencer, C. Murphy, Z. C. He, H. B. Wu, S. J. Su, Y. Cao, J. S. Kim, J. C. de Mello, D. D. C. Bradley and J. Nelson, Adv. Energy Mater., 2013, 3, 718-723.

23 K. D. G. I. Jayawardena, J. Fryar, S. Ravi, P. Silva and S. J. Henley, J. Phys. Chem. C, 2010, 114, 12931-12937.

24 S. J. Henley, J. Fryar, K. D. G. I. Jayawardena and S. R. P. Silva, Nanotechnology, 2010, 21.

25 H. Bronstein, E. Collado-Fregoso, A. Hadipour, Y. W. Soon, Z. Huang, S. D. Dimitrov, R. S. Ashraf, B. P. Rand, S. E. Watkins, P. S. Tuladhar, I. Meager, J. R. Durrant and I. McCulloch, Adv. Funct. Mater., 2013, 23, 5647-5654.

26 S. Beaupre and M. Leclerc, J. Mater. Chem. A, 2013, 1, 11097-11105.

27 C. H. Peters, I. T. Sachs-Quintana, J. P. Kastrop, S. Beaupre, M. Leclerc and M. D. McGehee, Adv. Energy Mater., 2011, 1, 491-494.

28 S. Cho, K. Lee and A. J. Heeger, Adv. Mater., 2009, 21, 19411944.

29 A. B. Djurisic and Y. H. Leung, Small, 2006, 2, 944-961. 